\title{
Enhancement of Airborne Particles Removal in a Hospital Operating Room
}

\author{
K. Y. Wong, H. M. Kamar* and N. Kamsah \\ Faculty of Engineering, Universiti Teknologi Malaysia, \\ 81310 Skudai, Johor, Malaysia \\ *Email: haslinda@mail.fkm.utm.my
}

\begin{abstract}
This article presents the results of a numerical study to examine the transport of particles in an operating room equipped with an Econoclean ventilation system. Its aims are to reduce the number of particles falling onto the operating table. A simplified CFD model of the operating room was developed and validated based on the measured air velocity distribution. An SST k- $\omega$ turbulent flow model was used to simulate the airflow, while a discrete phase model was used to simulate the movement of the airborne particles. The effects of the standing posture of the surgical staff on the settlement of the particles on the operating table were examined. Results show that under the present ventilation system, when the surgical staff bend forward at an angle of $45^{\circ}$, the number of airborne particles that tend to fall onto the operating table increased by 1.4-fold. Adding an exhaust grille to the operating room does not have any significant effects on the distribution of the airborne particles. However, when a larger air supply diffuser is also used, the number of airborne particles that settled on the operating table was reduced 4-fold. More airborne particles are transported towards the exhaust grilles, and more airborne particles accumulate below the operating table. The present study shows that the usage of large air supply diffuser in the operating room is capable of reducing the number of airborne particles fall onto the operating table. Also, it enhances the efficiency of airborne particle removal.
\end{abstract}

Keywords: Numerical method; bacteria-carrying particles; hospital operating room; surgical site infection; air supply system.

\section{INTRODUCTION}

Hospitals require a high level of cleanliness, particularly inside the operating rooms where surgeons perform surgical procedures on patients. Such requirements will protect patients from possible surgical site infection (SSI). Studies have shown that out of 100 operations, approximately seven patients (Sweden), fifteen patients (Brazil), five patients (Europe \& USA) and eleven patients (Vietnam) were infected with SSI [1-3]. The U.S. Department of Health and Human Services (HHS) estimated that there were more than 290000 incidences of SSI, and more than 13000 infected patients died annually [4]. SSI cause an undue financial burden, as the costs for post-surgical treatment are high, ranging from $\$ 400$ to $\$ 30,000$ depending on the types of infection [1]. SSI could occur either through direct contact or through the deposition of airborne bacteria-carrying particles (BCP) into the patient's wound. The probability of patients contracting an SSI through direct contact is quite low since all surgical instruments are sterilised before they are used. The deposition of airborne particles is hence identified as the primary cause of SSI. Studies have found that about $98 \%$ of infections in surgical wounds resulted from bacteria carried 
by airborne particles [5]. Staphylococcus aureus has been found to be the dominant SSIcausing bacteria species present in the operating room (OR) [6-8]. Methicillin-resistant Staphylococcus aureus (MRSA), Pseudomonas aeruginosa and Acinetobacter species have also been identified as causes of SSI [8]. Bacteria-carrying particles have sizes in the range of $10 \mu \mathrm{m}$ [9]. Particle sizes ranging from $5 \mu \mathrm{m}$ to $10 \mu \mathrm{m}$ can be considered as infectious particles inside the OR [10]. Hansen et al. (2005)[11] state that there is a close relationship between colony-forming units (CFUs) and particles of diameter larger than $5 \mu \mathrm{m}$. Subsequently, people tend to assume that particles with diameters of $5-10 \mu \mathrm{m}$ are infectious particles in the context of the OR [12-14].

In recent times, the majority of operating rooms equipped with mixed turbulent systems have inclined towards the use of cleanroom ventilation systems. Such systems use the laminar airflow (LAF) air-supply system together with high-efficiency particulate air (HEPA) filters or ultra-low penetration air (ULPA) filters. HEPA filters are capable of filtering out $99.97 \%$ of particles with diameters of $0.3 \mu \mathrm{m}$ and larger, whereas ULPA

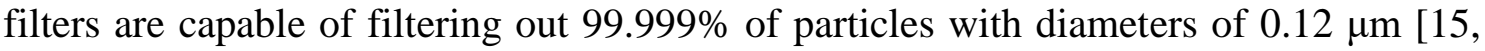
16]. The use of these filters is found to be very effective in eliminating airborne particles in a unidirectional clean air supply condition [16]. Operating rooms in many developing countries use ultraclean ventilation systems with ULPA filters [1, 14]. Such systems are capable of supplying clean air and provide high levels of comfort for medical staff [17]. However, perhaps because of the high construction and maintenance costs, ORs in Malaysian hospitals do not widely employ such systems. Instead, Econoclean systems with HEPA filters, which have lower capital and maintenance costs, are found in most ORs in Malaysia [18].

The guidelines for "Design and Construction of Hospital and Health Care Facilities" state that the air distribution pattern in the operating room is equally important as the air change rate per hour (ACH) [19]. The performance of two types of air supply system, namely vertical and horizontal systems, has been investigated by Sadrizadeh et al. (2014) [12]. They claimed that the horizontal air supply systems performed much better in removing airborne particles from the vicinity of the operating table. Sadrizadeh and Holmberg (2015) [1] also found that the addition of a portable ultraclean air supply system could further reduce the accumulation of airborne particles in the area close to the operating table.

This article presents a numerical study to investigate the transport of airborne particles inside an OR furnished with an Econoclean system in a private hospital in Malaysia. The phrase "Econoclean system" refers to one of the classifications of the aircooling system for the OR. So far, most of the studies have replaced the airborne particles as gaseous (fluid phase) during the simulation. In the present study, solid particles (discrete phase) were utilised in the simulation. The purpose is to reflect a more realistic condition of airborne particles' movements in the OR. The particles were assumed to be discharged from the exposed faces of the surgical staff at a given mass flow rate. The first objective is to examine the transport paths and concentration of the particles in the vicinity of the operating table. The second is to identify a ventilation strategy that will improve the removal of the particles from the OR. A simplified model of the operating room was developed using Fluent Computational Fluid Dynamics (CFD) software and validated for flow analysis. The CFD method has been used by many researchers as a tool to carry out flow analyses and predict airflow patterns inside hospital ORs. An SST k- $\omega$ turbulent model was employed to simulate the airflow, while a discrete phase model (DPM) was used to simulate the transport of the airborne particles. The study also proposed the ventilation strategy to reduce particle concentration in the area of the operating table. 


\section{METHODOLOGY}

\section{Field Measurement}

The field measurement was carried out when there was no surgical procedure taking place inside the operating room. The objective was to quantify the variation of airflow velocity inside the operating room. The data will also be used for validating the CFD flow models. The field measurement was conducted according to the procedures described in the ISO 14644-1 (1999) [20], IEST (1997) [21] and NEBB Procedural Standards for Certified Testing of Cleanroom (2009) [22] to ensure the reliability of the measured data. The operating room was set in fully functional condition 30 minutes before the field measurements was performed to assure steady-state operating conditions was achieved. All doors of the operating room were closed to avoid any changes in the airflow velocity and direction. The operating conditions were set to comply with the ISO 14644 standards, where the airflow velocity is $0.45 \mathrm{~m} / \mathrm{s}+/-20 \%$, air change rate is greater than 20 per hour, relative humidity is $55 \%+/-10 \%$, air temperature is $20 \circ \mathrm{C}+/-2 \circ \mathrm{C}$, and a room air pressure of greater than $5 \mathrm{~Pa}$. An Alnor EBT 731 micro-manometer with an error of $+/-$ $3 \%$ was used to measure the airflow velocity, as shown in Figure 1. The manometer is capable of measuring the mean airflow velocity at a large nominal face area of the supply air diffuser.

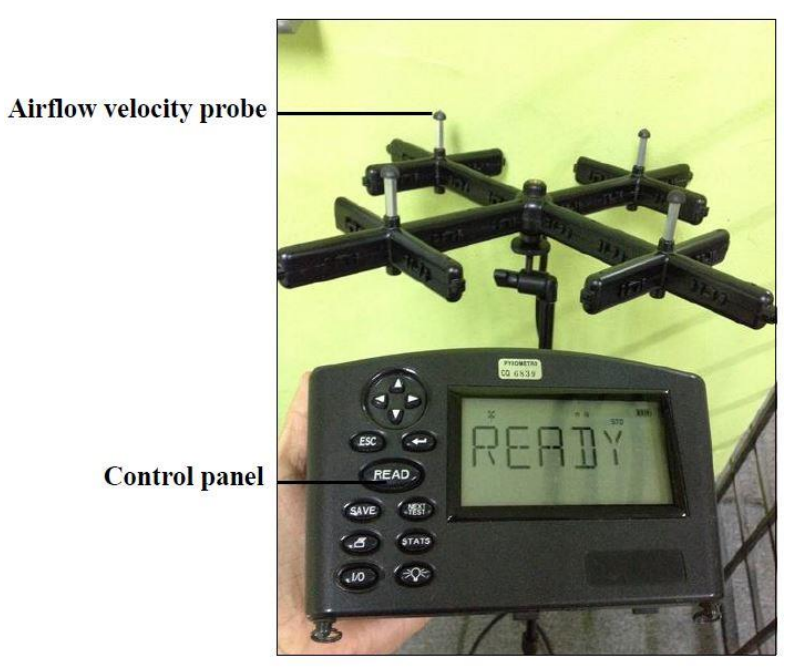

Figure 1. An Alnor balometer (EBT 731)

Before taking the measurement, a tape was used to mark the sampling points according to the generated grid. A total of 12 sampling zones were specified on one horizontal plane that is at the height of $1.2 \mathrm{~m}$ from the floor of the operating room. This zone is shown in Figure 2. Measurements of the airflow velocities were carried out according to the procedure described in IEST standards. Data sampling point was set at the center of each zone which has an area of $30 \mathrm{~m}^{2}$ [23]. The airflow velocity was recorded at every 1 minute time interval. A tripod was used to hold the measuring instrument to eliminate error due to any movement of the device. 


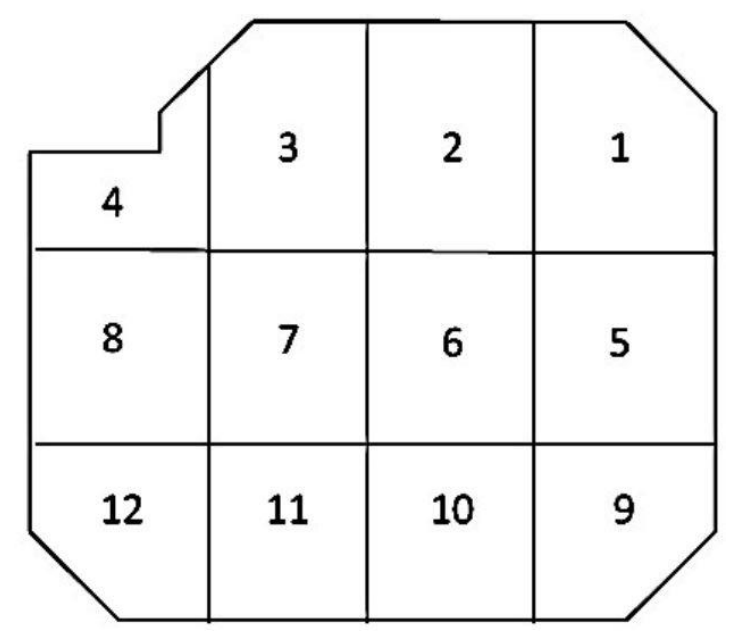

Figure 2. Sampling zones on the horizontal plane of $1.2 \mathrm{~m}$ from the floor. The numbers indicate the exact locations where the airflow velocity measurements were made.

\section{Description of The CFD Model}

Figure 3 shows a simplified CFD model of the hospital OR. The model includes a surgical lamp, an operating table, air supply diffusers and air exhaust grilles [24]. Although the surgical lamp was included, the effects of heat generated by the lamp on the airflow and particle movement were not considered. For simplification, other surgical equipment and furniture were not included in the CFD model. The air supply diffusers measure $1.2 \mathrm{~m}$ (W) $\times 0.6 \mathrm{~m}(\mathrm{~L})$, while the exhaust air grilles have dimensions of $0.22 \mathrm{~m}(\mathrm{~W}) \times 0.46 \mathrm{~m}$ (L). The size of the surgical lamp is $0.45 \mathrm{~m}(\mathrm{D}) \times 0.155 \mathrm{~m}(\mathrm{H})$. The major dimensions of the components are tabulated in Table 1 . There is a total of six air supply diffusers located at the ceiling of the operating room, directly above the operating table. They are designed such that the downward airflow covers the entire area of the operating table with a 305 $\mathrm{mm}$ offset on all sides of the table. This feature is to fulfil the requirement of the ASHRAE Standard 170 (2008) [25]. There are two entrances refer to the operating room: one for the surgical staff, which measures $0.9 \mathrm{~m}(\mathrm{~W}) \times 2.1 \mathrm{~m}(\mathrm{H})$, and the other for the patient, which measures $2.0 \mathrm{~m}(\mathrm{~W}) \times 2.1 \mathrm{~m}(\mathrm{H})$. Each of the exhaust grilles has an effective area of $0.084 \mathrm{~m}^{2}$. They are located in the middle of the four sides of the room wall, at a height of $0.25 \mathrm{~m}$ from the floor.

Table 1: Major dimensions of the components

\begin{tabular}{lc}
\hline Component & Dimension \\
\hline Operating room & $6.0 \mathrm{~m} \times 6.9 \mathrm{~m} \times 3.0 \mathrm{~m}($ Length $\times$ width $\times$ height $)$ \\
Exhaust grilles & $0.22 \mathrm{~m} \times 0.46 \mathrm{~m}($ Width $\times$ height $)$ \\
Surgical lamp & $0.45 \mathrm{~m} \times 0.15 \mathrm{~m}($ Diamter $\times$ height $)$ \\
Patient entrance & $2.0 \mathrm{~m} \times 2.1 \mathrm{~m}($ Width $\times$ height $)$ \\
Personnel entrance & $0.9 \mathrm{~m} \times 2.1 \mathrm{~m}($ Width $\times$ height $)$ \\
\hline
\end{tabular}

The operating room is furnished with a vertical downward cooling air-flow system, which is in compliance with Standard 170. This standard requires that the air supply diffusers be equipped with HEPA filters mounted on the ceiling, directly above the operating table, while the exhaust air grilles are to be installed on the corner walls, at 
least $203 \mathrm{~mm}$ above the floor. Additionally, less than $30 \%$ of the operating room's ceiling grid area must be spared to occupy the boom mounts and lighting.

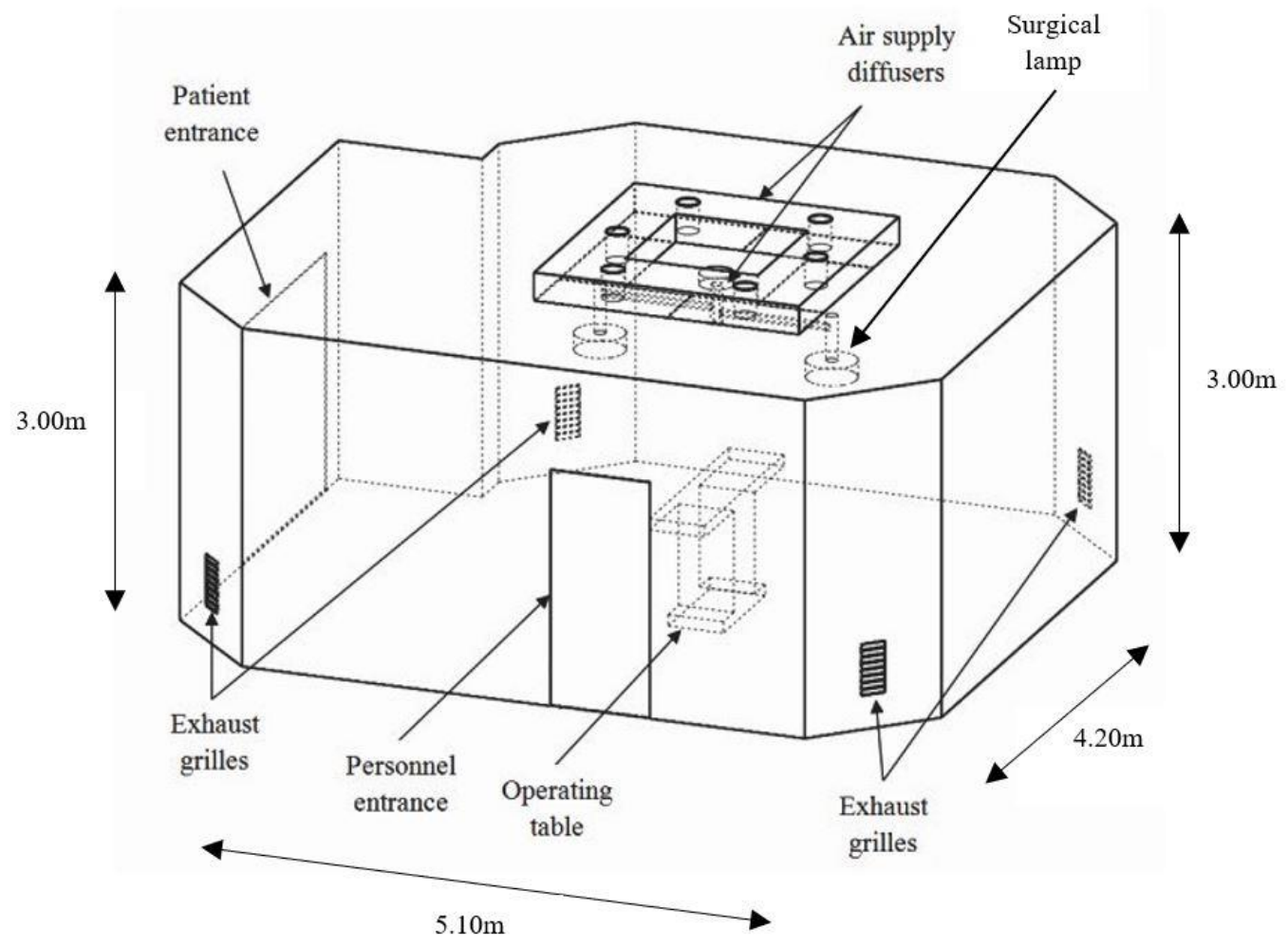

Figure 3. Simplified CFD model of the operating room with major dimensions.

\section{Meshing the Computational Domain}

The ANSYS ICEM software was used to mesh the computational domain of the CFD model. Tetrahedral elements of three different sizes were used: coarse, medium and fine. The fine elements were utilized in areas where there are significant variations in the airflow field, while coarser elements were employed in areas with relatively little change in the airflow. The element size in regions where there is a large variation in the results should be ten times smaller than the element size in the surrounding areas [26]. In this study, elements with finer size were used in the area close to the air supply diffusers, the exhaust air grilles, the operating table and the surgical lamps. Larger elements were utilized in the region surrounding these areas. Medium size elements were used in the remaining sections of the computational domain. The skewness of the meshing grid is 0.9. The minimum and maximum element sizes are $3.85 \times 10^{-4} \mathrm{~m}$ and $7.25 \times 10^{-2} \mathrm{~m}$, respectively.

A grid independence test (GIT) was carried out, and a grid convergence index (GCI) was determined to establish the number of elements that would minimize the effects of meshing on the results of the simulations. For the GIT, five sets of element numbers were tested, namely from 220,000 up to 3,520,000 elements. The airflow velocity for 100 points uniformly distributed on an $\mathrm{x}$-axis line at $1.2 \mathrm{~m}$ above floor level was selected in the model. The airflow velocity magnitude versus the distance along the $\mathrm{x}$-axis line was plotted, as shown in Figure 4. It can be seen that the airflow velocity was nearly unchanged when 880,000 elements were used to mesh the computational domain. 


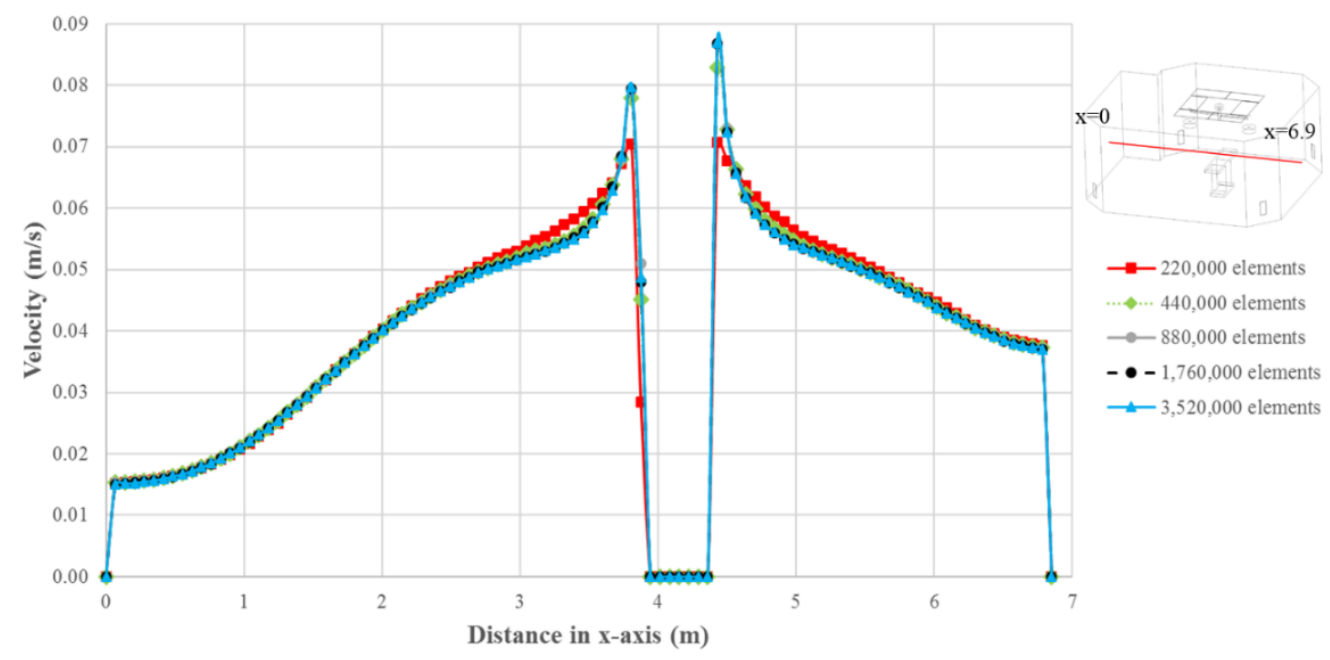

Figure 4. The variation of airflow velocity versus the distance along a line.

The determination of the GCI was based on Sadrizadeh et al. [27], Kwasniewski [28] and Karimi et al. [29], as given in Eq. (1) below:

$G C I(u)=\frac{F_{s} \varepsilon_{r m s}}{r^{p}-1}$

where $F_{s}$ is the safety factor, with a value of $3, \varepsilon$ is the relative difference between subsequent solutions, $p$ is the order of convergence, with a value of 2 , and $r$ is the ratio of the amount of the fine grids to that of coarse grids. The safety factor $F_{s}$ was arbitrarily set based on the accumulated experience on CFD calculations [28]. It represents 95\% confidence for the estimated error bound. The $\varepsilon$ was defined as given by Eq. (2)[27]:

$\varepsilon_{r m s}=\sqrt{\frac{\sum_{i=1}^{n}\left(\left(u_{i, \text { coarse }}-u_{i, \text { fine }) / u_{i, \text { fine }}}\right)^{2}\right.}{n}}$

where $f$ is the airflow velocity. The values of the GCI for meshing with $440,000,880,000$, $1,760,000$ and $3,520,000$ elements were found to be $6.2 \%, 3.3 \%, 0.5 \%$ and $0.3 \%$, respectively. Thus, 880,000 tetrahedral elements with non-structured meshing were considered adequate for the airflow and particle movement simulations. To further ensure that the mesh was sufficiently fine, the dimensionless wall distance $(y+)$ was kept below five.

\section{Selection of Airflow and Particle Movement Models}

The governing equations that describe the fluid flow and particle concentration within an enclosure are all based on the conservation of mass, momentum, energy and species concentration within the enclosure. Several flow models are available in the CFD software to simulate the airflow inside the computational domain. These are ReynoldsAveraged Navier- Stokes (RANS) family equations, which include the $\mathrm{k}-\varepsilon, \mathrm{k}-\omega$, transition SST, detached eddy simulation (DES) and large eddy simulation (LES) models. The application of DES and LES for flow simulation in an indoor environment requires high computational power and longer computation time as compared to the RANS family models. For a steady-state simulation of airflow, many studies found in the literature 
indicate that the RANS model is adequate to give sufficiently reliable results $[1,12,27$, 30-32].

In this study, all the above flow models were examined under a steady-state condition to find out which flow model is the most suitable to be used in the proceeding airflow simulations. This analysis was done by performing the simulations on the base case model of the operating room using each of the flow models. Airflow velocity of 0.45 $\mathrm{m} / \mathrm{s}$ was prescribed at all the air supply diffusers as the boundary conditions. A zero gauge pressure boundary condition was specified at all the air outlet grilles. The air temperature, density, dynamic viscosity and kinematic viscosity are at $19^{\circ} \mathrm{C}, 1.209 \mathrm{~kg} / \mathrm{m}^{3}, 1.816 \times 10^{-}$ ${ }^{5} \mathrm{Ns} / \mathrm{m}^{2}$, and $1.502 \times 10^{-5}$, respectively. A no-slip condition was defined at all the wall surfaces. Airflow simulations were performed on the CFD model repeatedly, using different flow models. The boundary conditions applied to the CFD model of the operating room are tabulated in Table 2.

Table 2: Boundary conditions applied to the CFD model of the operating room.

\begin{tabular}{lcc}
\hline Location & Type & Setup \\
\hline Air supply diffuser & & Velocity magnitude: $0.45 \mathrm{~m} / \mathrm{s}$ \\
& Velocity inlet & $\begin{array}{c}\text { Direction of airflow: Normal to the boundary } \\
\text { Turbulence intensity: } 5 \% \\
\text { DPM: Escape }\end{array}$ \\
& Pressure outlet & Gauge pressure: 0 Pa \\
Exhaust grille & DPM: Escape
\end{tabular}

Figure 5 shows the comparison of the airflow velocity magnitudes at all the measuring points on the horizontal plane at a height of $1.2 \mathrm{~m}$ from the floor, obtained for the flow models. The results were compared with the airflow velocities obtained from the field measurement at all the measuring points. It was found that the Realizable k- $\varepsilon$ flow model has an average deviation of about $10 \%$ compared to the measured airflow velocities. The SST k- $\omega$ flow model has an average difference of about $8 \%$, while the SST k-kl- $\omega$ and SST transition models both have an average deviation of about $10 \%$. Finally, the standard k- $\omega$ flow model has an average difference of about $16 \%$. These findings suggest that the k- $\omega$ family flow models produced smaller average deviations in the airflow velocity magnitudes compared to the k- $\varepsilon$ family models. Among all flow models, the SST k- $\omega$ produces airflow velocities closest to the measured values. Therefore, this model was chosen and used in the proceeding CFD simulations. 


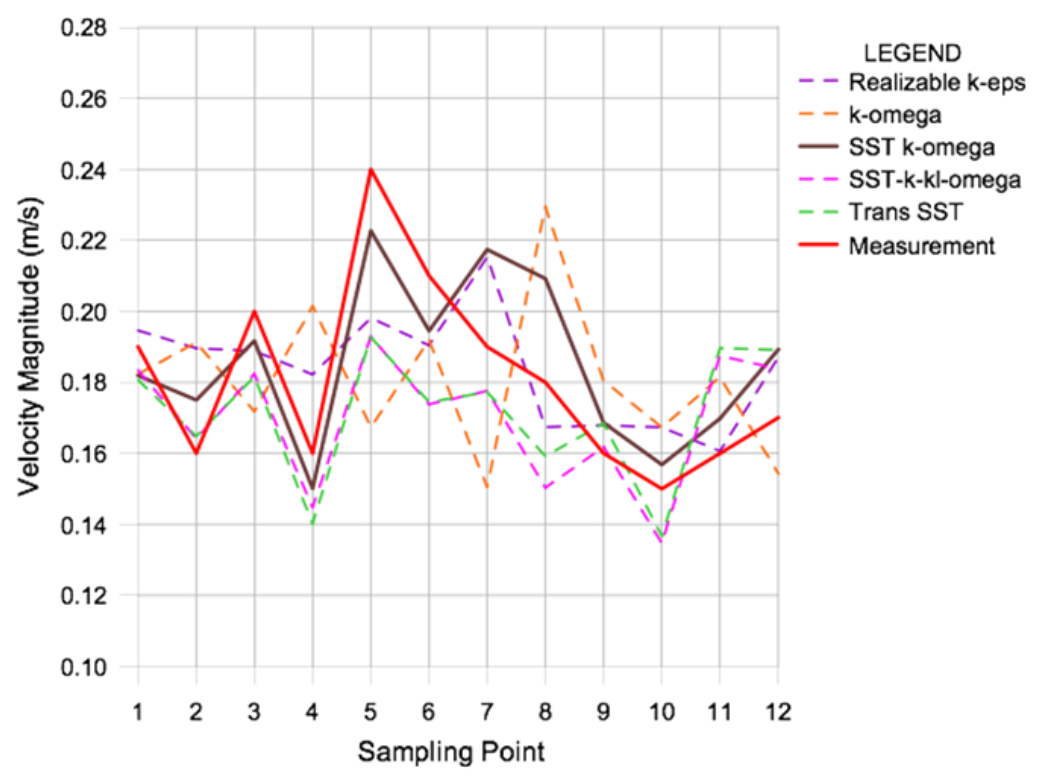

Figure 5. Comparison between the measured and predicted airflow velocity variation on a plane of $1.2 \mathrm{~m}$ height from the floor, using the $\mathrm{k}-\varepsilon$ and $\mathrm{k}-\omega$ family flow models.

The governing equations for the SST k- $\omega$ model are given by Eq. (3) and Eq. (4) below [33]:

$\partial(\rho \mathrm{k}) / \partial \mathrm{t}+\partial\left(\rho \mathrm{uu}_{\mathrm{i}}\right) / \partial \mathrm{x}_{\mathrm{i}}=\partial\left(\Gamma_{\mathrm{k}} \partial \mathrm{k} / \partial \mathrm{x}_{\mathrm{j}}\right) / \partial \mathrm{x}_{\mathrm{j}}+\hat{\mathrm{G}}_{\mathrm{k}}-\mathrm{Y}_{\mathrm{k}}+\mathrm{S}_{\mathrm{k}}$

$\partial(\rho \omega) / \partial \mathrm{t}+\partial\left(\rho \omega u_{i}\right) / \partial \mathrm{x}_{\mathrm{i}}=\partial\left(\Gamma_{\omega} \partial \omega / \partial \mathrm{x}_{\mathrm{j}}\right) / \partial \mathrm{x}_{\mathrm{j}}+\mathrm{G}_{\omega}-\mathrm{Y}_{\omega}+\mathrm{D}_{\omega}+\mathrm{S}_{\omega}$

where $\rho$ is fluid density, $t$ is time, $\underline{u}_{\mathrm{i}}$ is velocity component, $x_{\mathrm{i}}$ is the coordinate, $\mu$ is fluid viscosity, $k$ is kinetic energy, $\omega$ is the specific rate of dissipation, $\Gamma$ is effective diffusivity, $G$ is the generation of turbulence kinetic energy, $Y$ is dissipation due to turbulence, $D$ is a cross-diffusion term and $S_{\mathrm{i}}$ is a source term.

A pressure-based segregated algorithm was adopted in this study since the airflow is assumed to be incompressible and with relatively low velocity. Also, a coupled algorithm was selected for the pressure-velocity coupling, since it is suitable to handle single-phase and steady-state flow conditions. Additionally, a double-precision option was chosen for the numerical scheme, since it promotes less iterative error. In this study, the simulation was performed in a steady-state condition with a second-order upwind discretization scheme. The discretization scheme was selected as second-order upwind to reduce the effects of numerical diffusion on the solution, as this would help to improve the accuracy. The field variables (stored at cell centres) were interpolated to the faces of the control volumes. An absolute residual value for all equations was set to $1 \times 10^{-5}$ for all the conservation equations. The convergence of the airflow velocity is shown in Figure 6. 


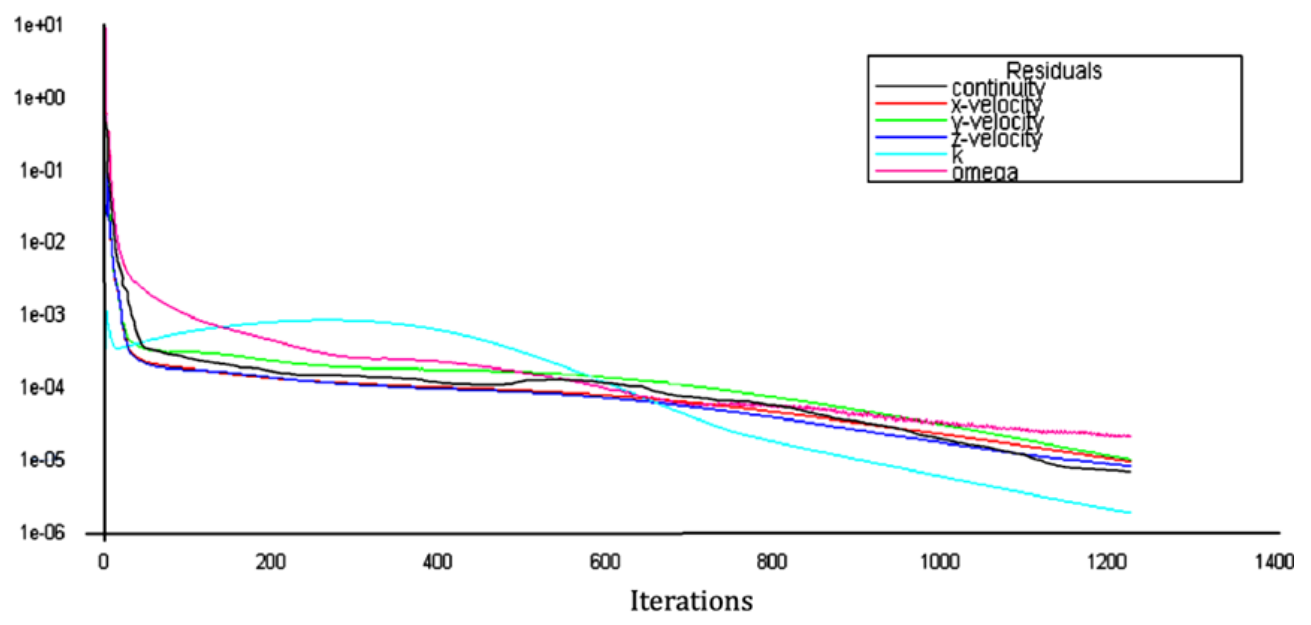

Figure 6. Convergence history.

Two models are available for simulating the movement of airborne particles, namely the discrete phase model (DPM) and the multiphase model. Both models calculate the flow field according to the Eulerian framework, while the particle phases are solved differently. The particle phases of DPM are solved based on the Lagrange approach. In this study, this model was used for simulating the movement of airborne particles in the computational domain. In this model, the fluid phase was treated as a continuum that was analysed by solving the time-averaged Navier-Stokes equations. The discrete phase was resolved by tracking a large number of particles through the calculated flow field. The DPM is appropriate for particles that occupy a volume fraction of less than $10 \%$ regardless of its mass fraction [34]. Many studies have shown that this model is reliable to be used in modelling particle movement $[1,6,12]$.

In this study, the aerodynamic diameter of the particles was chosen as $5 \mu \mathrm{m}$, and their density was $2 \mathrm{~g} / \mathrm{cm}^{3}$ [30]. The particles were considered to be released from the frontal exposure area of the surgical staff at a rate of $1.31 \times 10^{-12} \mathrm{~kg} / \mathrm{s}$. The particles released rate was acquired by Liu et al. [30]. For the particle boundary conditions, an escape condition was specified at the air supply diffusers and exhaust grilles, while a trap condition was set on the expose surfaces of the operating table, walls and surgical lamps. The trap boundary condition means that once a particle touches the area, it is caught, and the particle tracking process stops. The escape boundary condition means that when the particle exit through the area, the trajectory calculations are terminated. The DPM model is capable of handling the effects of diverse forces such as Brownian force, gravitational force, Saffman lift force, etc. [33]. The effect of Saffman force was disregarded in this study, since the airborne particles are relatively small in $(5 \mu \mathrm{m})$, as reported in Saidi et al. (2014) [35]. The Saffman force is only significant when the particles involved in the flow simulation are sufficiently large (greater than $10^{-6} \mathrm{~m}$ ).

The Brownian motion force was also abandoned due to its non-significance in comparison to turbulent diffusivity $[12,14,36]$. Forces such as gravitational force and drag, which have been reported to have important effects on micro-sized particles, are considered [37, 38]. The discrete random walk (DRW) model was incorporated to simulate the stochastic airflow velocity fluctuations. This model assumes that the fluctuating velocities follow a Gaussian probability distribution. The force balance equation for discrete phase model then becomes [1, 12],

$$
d u_{p} / d t=F_{D}\left(u-u_{p}\right)+g\left(1-\rho / \rho_{p}\right)+F_{a}
$$


where $F_{D}\left(u-u_{\mathrm{p}}\right)$ represents the drag force, $u$ is fluid velocity, $u_{\mathrm{p}}$ is particle velocity, $g$ is gravity force, $\rho$ is fluid density, $\rho_{\mathrm{p}}$ is particle density, and $F_{\mathrm{a}}$ is the additional force.

\section{Proposed Modification of The Ventilation System}

The presently installed ventilation system in the actual operating room was designed based on an ISO 14644 Standard 170-2013 - Minimum Guidelines for a Modern Operating Room. In this study, a minor modification to the present ventilation system is proposed in an attempt to improve the particle removal capability of the system, particularly from the vicinity of the operating table [4]. Two minor modifications are proposed: the first is the addition of one air exhaust grille mounted on one of the room's walls and the second is the use of a much larger ceiling-mounted air supply diffuser. The airflow velocity at the diffuser remains the same, at $0.45 \mathrm{~m} / \mathrm{s}$. With the larger area, the air volume flow rate will increase. Figure 7 shows a simplified CFD model of the operating room which incorporates the two proposed modifications to the ventilation system.

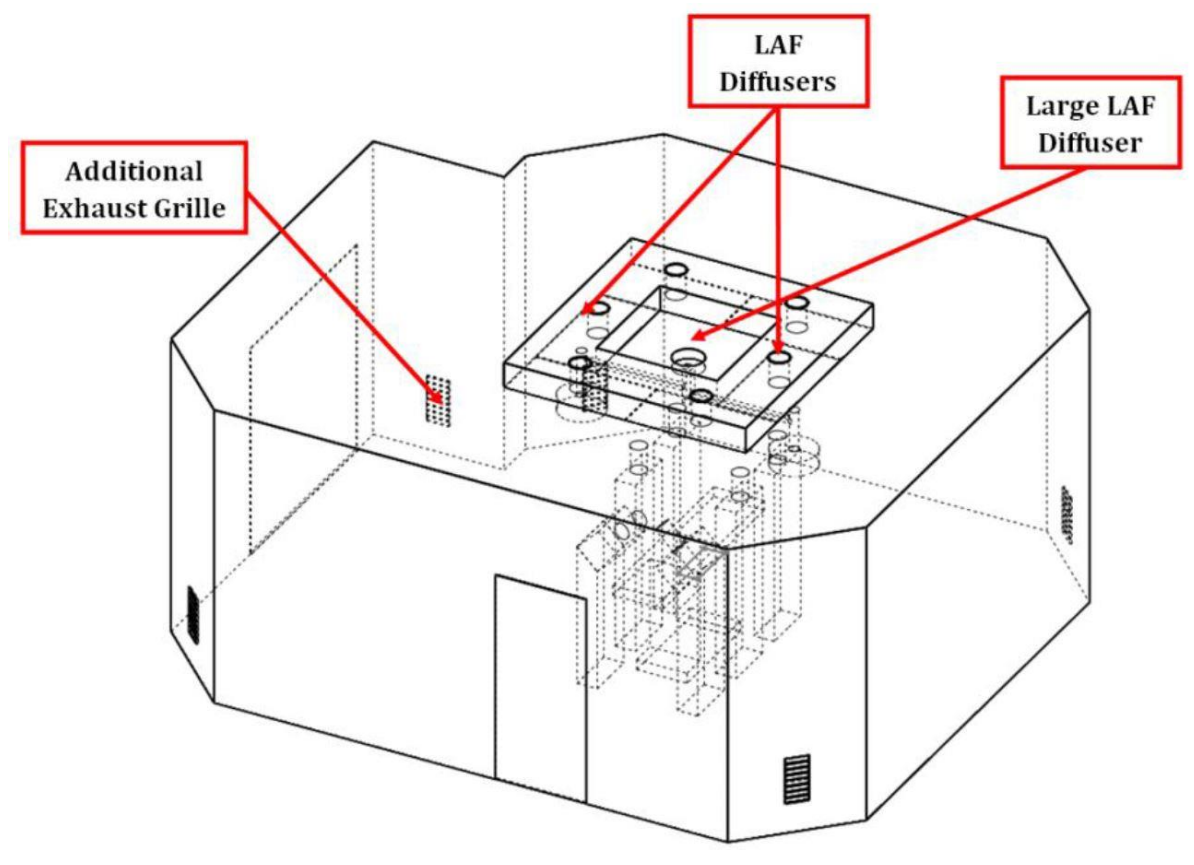

Figure 7. A simplified CFD model of the operating room with the proposed modifications on the ventilation system.

\section{RESULTS AND DISCUSSION}

\section{Variation of Airflow Velocity}

Figure 8 shows the effects of the proposed modification of the ventilation system on the airflow distribution in the same vertical plane when both the surgical staff are bending forward. Figure 8 (a) shows the variation of airflow velocity under present ventilation. Whereas, Figure 8 (b) shows the variation of the airflow velocity when the operating room is furnished with an additional air exhaust grille. It can be seen from this figure that there are no noticeable changes in the airflow velocity resulting from this modification. The magnitudes of the airflow velocity at the rear of both surgical staff and in the area between them appear to be similar to those shown in Figure 8 (a). However, when a combination 
of a new exhaust grille and a larger air supply diffuser is employed, the airflow velocity distribution shows a very significant increment. The airflow velocity at the rear of both surgical staff rises to about $0.23 \mathrm{~m} / \mathrm{s}$, while the airflow velocity in the area between the staff increases to $0.2 \mathrm{~m} / \mathrm{s}$. This represents a two-fold increment when compared to the same case under the present ventilation system. In summary, the first proposed modification to the ventilation system does not have any appreciable effects on the airflow distribution. However, when that change is combined with a larger air supply diffuser, a significant increase in the airflow velocity distribution is achieved, especially in between the surgical staff who are bending forward, which is not desired.

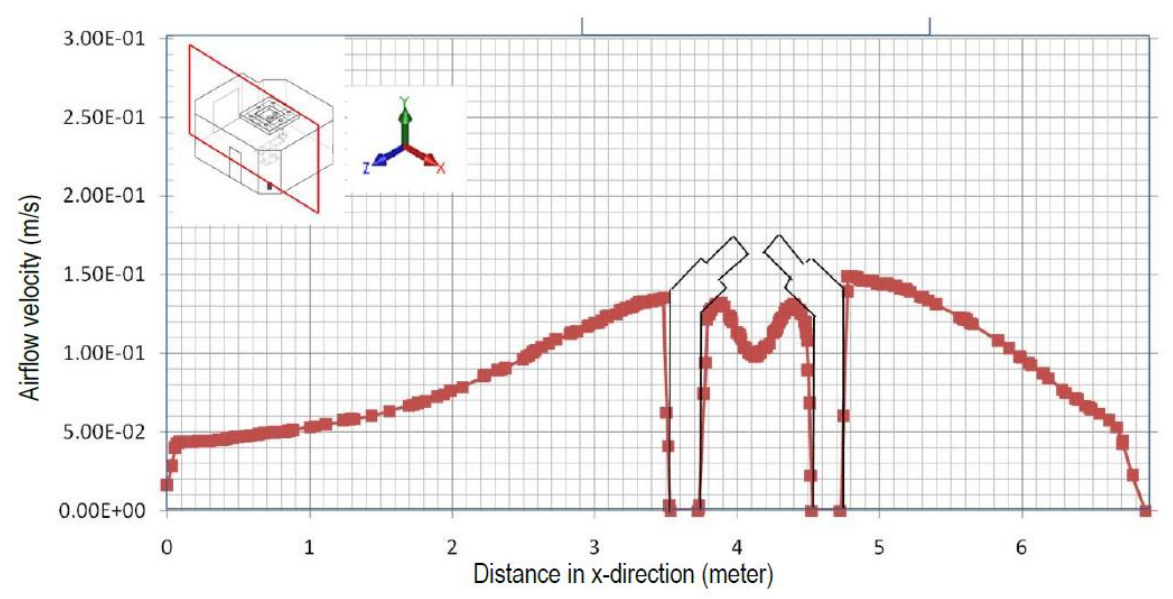

(a)

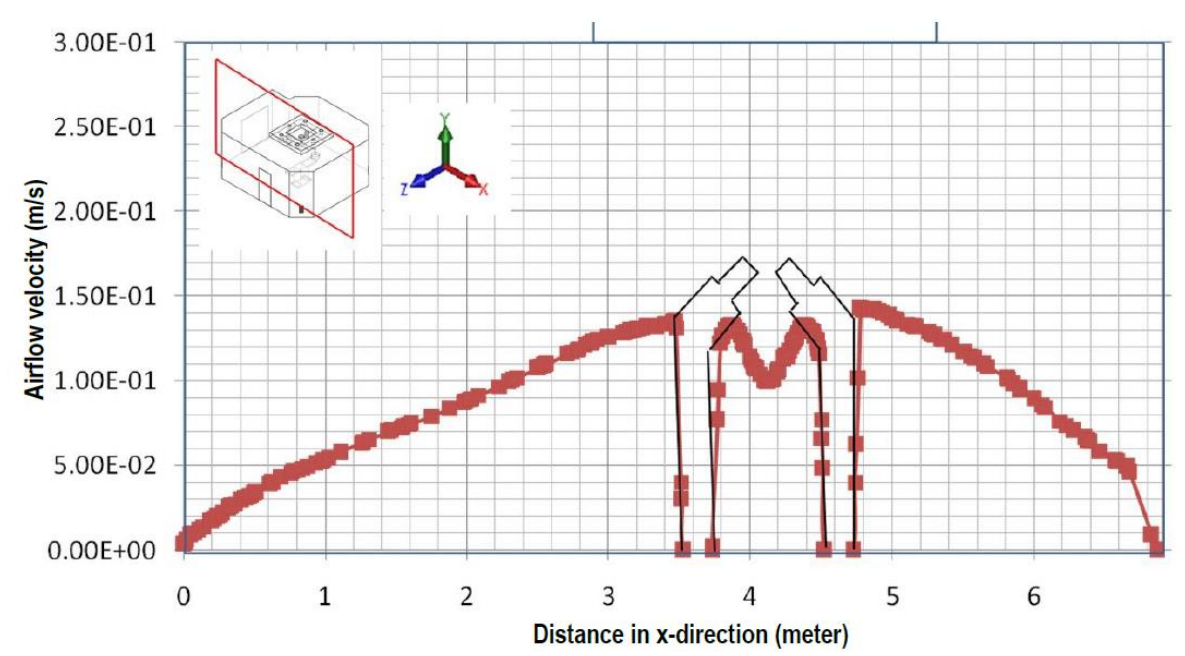

(b) 


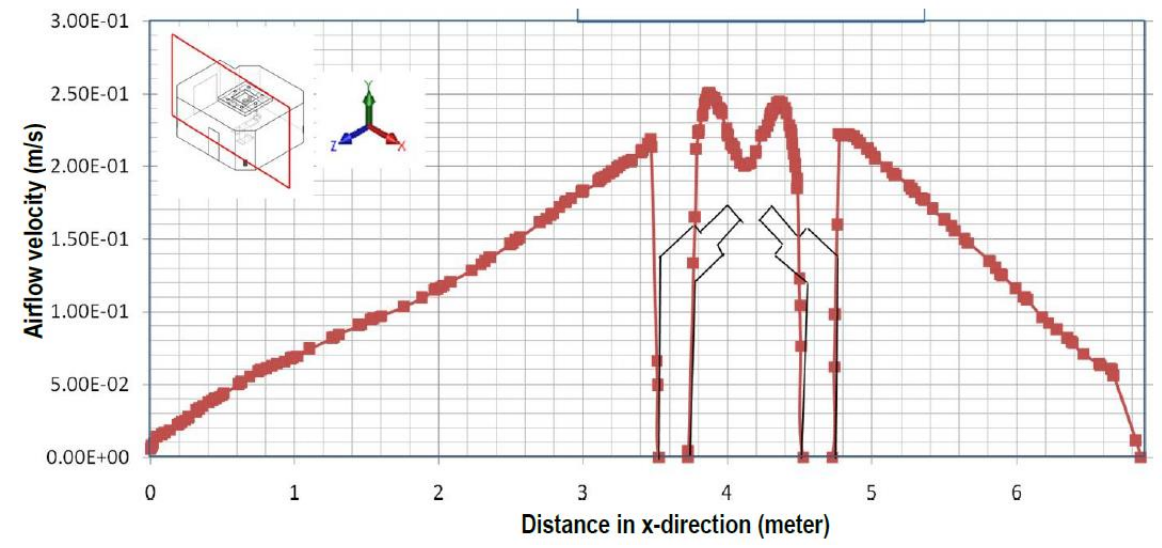

(c)

Figure 8. Variation of airflow velocity magnitude in a vertical plane with the proposed modified ventilation system, when both surgical staffs bend forward (a) with the present ventilation system, (b) with an additional exhaust grille, and (c) with a combination of additional exhaust grille and larger air supply diffuser.

\section{Variation of Particle Concentration}

Figure 9 shows the variation in the concentration of the airborne particles in a vertical plane that passes through the two surgical staff standing at the head-end of the operating table under the present ventilation system. It can be observed from Figure 9(a) that the particles fell from all the surgical staff and were transported away towards the exhaust air grilles. A larger number of particles appear to be washed away from the left surgical staff member compared to the one on the right. The concentration of particles around the two surgical staff reached a peak value of about $2.5 \times 10^{-5} \mathrm{mg} / \mathrm{m}^{3}$. It can also be observed from Figure 9(b) that larger numbers of airborne particles fall onto the operating table when two surgical staff are bending forward. These findings indicate that the accumulation of airborne particles on the operating table is affected by the standing posture of the surgical staff. High accumulation of airborne particles in this area is undesirable, as this would increase the possibility that the particles would settle on the patient. In the actual surgical procedure, this would increase the risk of the patient being infected by the bacteria carried by the falling particles.

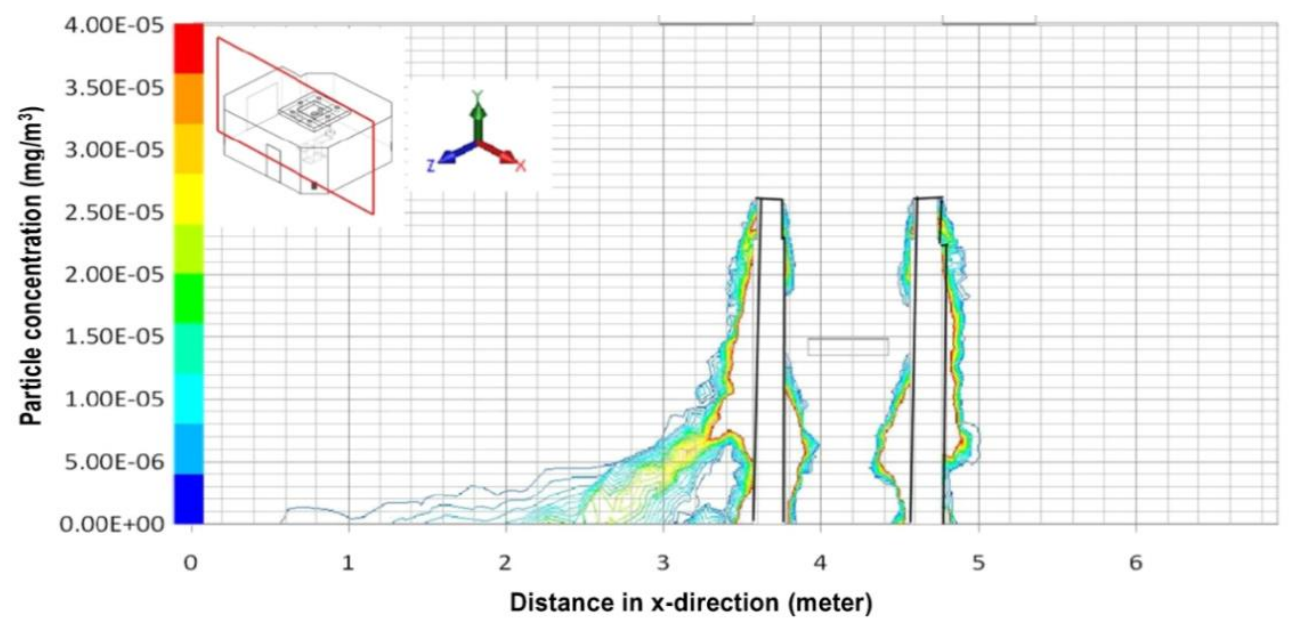

(a) 


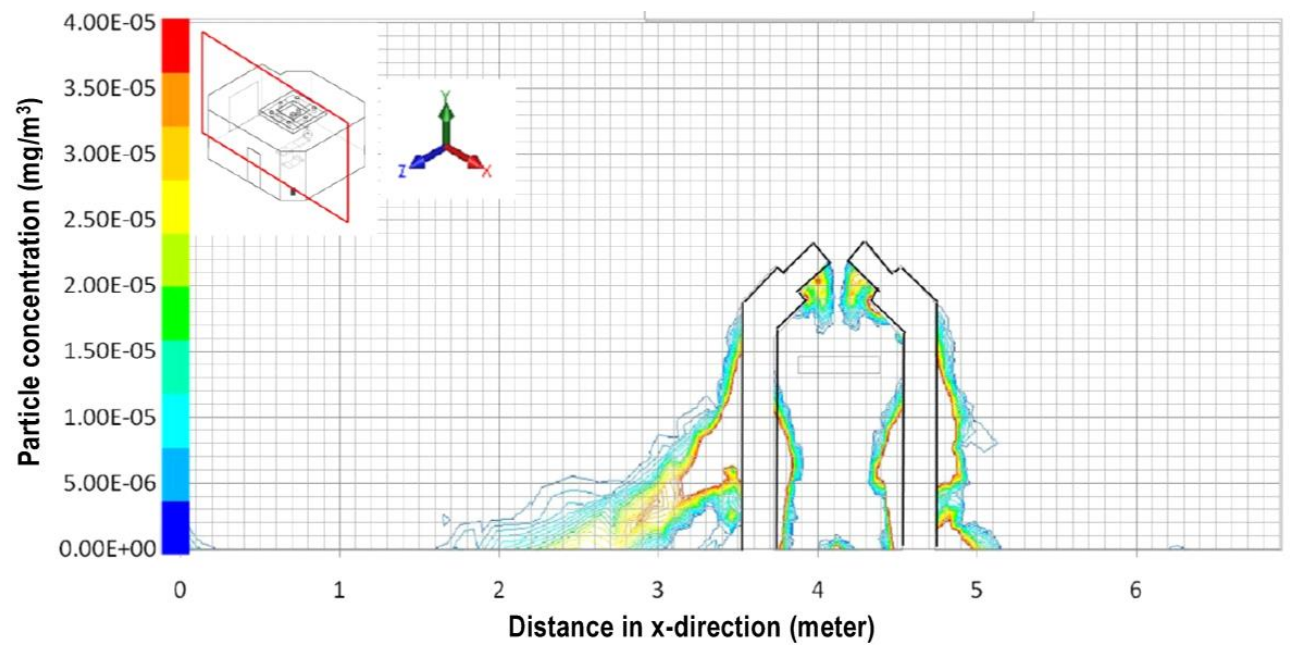

(b)

Figure 9. Variation of particle concentration on a vertical plane under (a) six surgical staff standing upright, (b) two surgical staff bending forward at $45^{\circ}$.

In summary, with the present ventilation system, when all the surgical staff are standing upright, almost no airborne particles appear to fall onto the operating table. However, when two surgical staffs who are standing opposite to one another bend forward, the number of particles that fall onto the operating table increases dramatically. The present ventilation system is incapable of washing away the airborne particles from the area of the operating table when the surgical staff are bending forward.

Figure 10 shows the variation in the concentration of airborne particles in the same vertical plane when two surgical staff are leaning forward at a $45^{\circ}$ angle under the proposed modified ventilation system. It can be observed from Figure 10(a) that, when an additional air exhaust grille is placed in one corner of the room, the variation in concentration of the airborne particles around the surgical staff is not greatly affected. Also, the transport paths of the particles appear very similar to those found under the present ventilation system. However, when a larger air supply diffuser is combined with the additional air exhaust grille, fewer particles are transported towards the exhaust grille on the left side of the room, as observed in Figure 10(b). Also, more particles appear to accumulate below the operating table. These particles can be transported upward and end up settling on the operating table, which is not desirable. The concentration of particles around the two surgical staff is reduced. With higher airflow velocity in this area, more particles tend to be transported away towards the exhaust air grilles. The most important effect is that the number of particles that fall onto the operating table is significantly reduced, but more particles are accumulating under the operating table. 


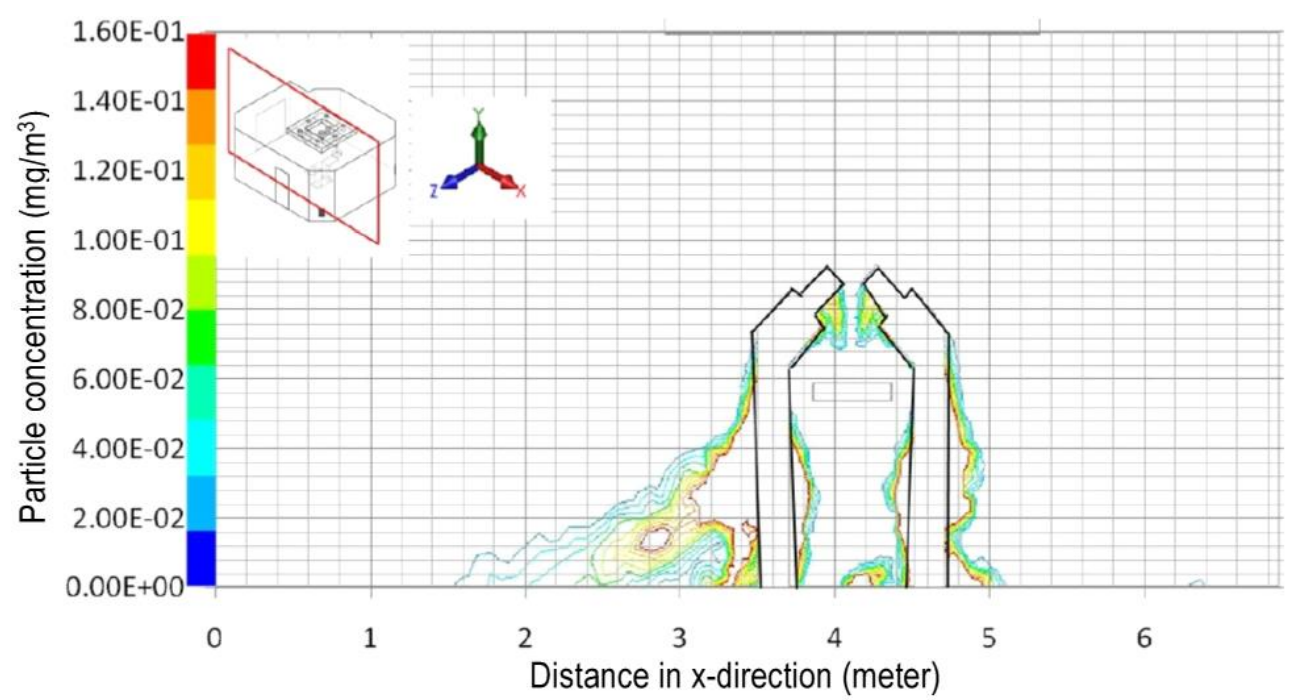

(a)

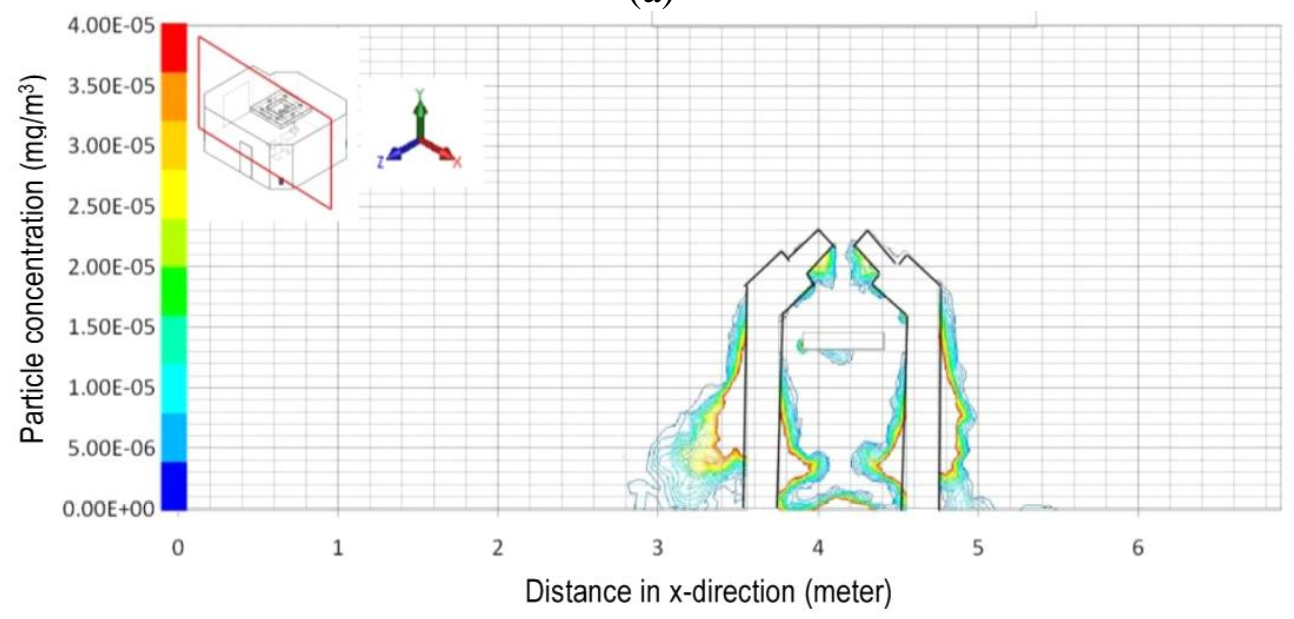

(b)

Figure 10. Variation of particle concentration on a vertical plane with two surgical staffs bend forward: (a) with additional air exhaust grille and (b) with the combination of additional air exhaust grille and a large air supply diffuser.

\section{CONCLUSION}

A computational fluid dynamic method was used to carry out simulations to predict the airflow distribution and the movement of airborne particles in a hospital operating room equipped with an Econoclean ventilation system. The goal was to reduce the accumulation of airborne particles on the operating table. Results show that under the present ventilation system, when the surgical staff bend forward at a $45^{\circ}$ angle, the number of airborne particles that tend to fall onto the operating table increases. Modifying the present ventilation system by adding an exhaust grille to the operating room does not have any significant effects on the distribution of the airborne particles. However, when this modification is combined with the use of a larger air supply diffuser, more airborne particles are transported towards the exhaust grilles. The number of airborne particles falling onto the operating table appears to be decreased, as a larger proportion of them are accumulating below the operating table. 


\section{ACKNOWLEDGEMENT}

The authors would like to express their appreciation for the support of Ainuddin Wahid Scholarship throughout this study under the Vot No. A.J10000.5900.06000.

\section{REFERENCES}

[1] Sadrizadeh S, Holmberg S. Effect of a portable ultra-clean exponential airflow unit on the particle distribution in an operating room. Particuology, 2015, 18:170178.

[2] Melhado MA, Hensen J, Loomans M. Review of ventilation systems in operating rooms in view of infection control. In: Proceedings of the 6th Int. Postgraduate Research Conf.. in the Built and Human Environment, Technische Universiteit Delft, 2006; pp. 478-487.

[3] Nguyen D, MacLeod WB, Phung DC, Cong QT, Nguyen VH, Hamer DH. Incidence and predictors of surgical-site infections in Vietnam. Infection Control \& Hospital Epidemiology, 2001. 22: 485-492.

[4] Wagner JA, Schreiber KJ. Improving operating room contamination control. Ashrae Journal, 2014, 56, 18.

[5] Whyte W, Hodgson R, Tinkler J. The importance of airborne bacterial contamination of wounds. Journal of Hospital Infection 1982; 3: 123-135.

[6] Sadrizadeh S, Holmberg S, Tammelin A. A numerical investigation of vertical and horizontal laminar airflow ventilation in an operating room. Building and Environment 2014; 82: 517-525.

[7] Whyte W, Cleanroom technology: fundamentals of design, testing and operation: West Sussex: John Wiley \& Sons; 2010.

[8] Buang S, Haspani M. Risk factors for neurosurgical site infections after a neurosurgical procedure: a prospective observational study at Hospital Kuala Lumpur. Medical Journal of Malaysia 2012; 67, 393-398.

[9] Memarzadeh F, Manning AP. Comparison of operating room ventilation systems in the protection of the surgical site. ASHRAE Transactions 2012; 108: 3-15.

[10] Memarzadeh F. Reducing risks of surgery, ASHRAE Journal 2003; 45: 28.

[11] Hansen D, Krabs C, Benner D, Brauksiepe A, Popp W. Laminar air flow provides high air quality in the operating field even during real operating conditions, but personal protection seems to be necessary in operations with tissue combustion. International Journal of Hygiene and Environmental Health 2005; 208: 455-460.

[12] Sadrizadeh S, Tammelin A, Ekolind P, Holmberg S. Influence of staff number and internal constellation on surgical site infection in an operating room. Particuology 2014; 13: 42-51.

[13] Emmerich SJ, Heinzerling D, Choi J, Persily AK, Multizone modeling of strategies to reduce the spread of airborne infectious agents in healthcare facilities. Building and Environment 2013; 60: 105-115.

[14] Chow TT, Wang J, Dynamic simulation on impact of surgeon bending movement on bacteria-carrying particles distribution in operating theatre. Building and Environment 2012; 57: 68-80.

[15] Wong KY, Kamar HM, Kamsah N, Zawawi FM, Tan H, Musa MN, et al., Correlation between particulate matter and microbial counts in hospital operating rooms. Advances in Environmental Biology 2018; 10: 1-4. 
[16] Kamsah N, Kamar HM, Alhamid MI, Wong KY. Impacts of temperature on airborne particles in a hospital operating room. Journal of Advanced Research in Fluid Mechanics and Thermal Sciences 2018; 44: 12-23.

[17] Wong KY, Kamar HM, Nazri K, Alia SN. Effects of surgical staff turning motion on airflow distribution inside a hospital operating room. Evergreen 2019; 6: 5258.

[18] Kamar HM, Kamsah N, Wong KY, Musa MN, Deris MS. Field measurement of airborne particulate matters concentration in a hospital's operating room. Jurnal Teknologi (Science \& Engineering) 2015; 77: 63-67.

[19] Ninomura P, Rousseau C, Bartley J, Updated guidelines for design and construction of hospital and health care facilities. ASHRAE Journal 2006; 48: H33, 2006.

[20] Standard ISO, ISO 14644-1, Cleanrooms and associated controlled environments, in classification of air cleanliness vol. ISO 14644-1, Cleanrooms and associated controlled environments, ed. United Kingdom: Institute of Environmental Sciences and Technology, 1999.

[21] Standard IEST, IEST-RP-CC006.2, in testing Cleanrooms vol. IEST-RPCC006.2, ed. USA: Institute of Environmental Sciences and Technology, 1997.

[22] Standard NEBB, Procedural standards for certified testing of cleanrooms, in Adjusting. and Balancing of Environmental Systems vol. Procedural standards for certified testing of cleanrooms, ed. USA: National Environmental Balancing Bureau, 2009.

[23] Xu T, Lan CH, Jeng MS, Performance of large fan-filter units for cleanroom applications. Building and Environment 2007; 42: 2299-2304.

[24] Woloszyn M, Virgone J, Mélen S, Diagonal air-distribution system for operating rooms: experiment and modeling. Building and Environment 2004; 39: 11711178.

[25] Standard ASHRAE, Standard 170 - 2008, in Ventilation of health care facilities vol. Standard 170 - 2008, ed. USA: The American Society of Heating, Refrigerating and Air-Conditioning Engineers, 2008.

[26] Villafruela J, Olmedo I, De Adana MR, Méndez C, Nielsen PV, CFD analysis of the human exhalation flow using different boundary conditions and ventilation strategies. Building and Environment 2013; 62: 191-200.

[27] Sadrizadeh S, Holmberg S, Nielsen PV. Three distinct surgical clothing systems in a turbulent mixing operating room equipped with mobile ultraclean laminar airflow screen: A numerical evaluation. Science and Technology for the Built Environment 2016; 22: 337-345.

[28] Kwaśniewski L. Application of grid convergence index in FE computation. Bulletin of the Polish Academy of Sciences: Technical Sciences 2013; 61, 123128.

[29] Karimi M, Akdogan G, Dellimore KH, Bradshaw SM. Quantification of numerical uncertainty in computational fluid dynamics modelling of hydrocyclones. Computers \& Chemical Engineering 2012; 43: 45-54.

[30] Liu J, Wang H, Wen W. Numerical simulation on a horizontal airflow for airborne particles control in hospital operating room. Building and Environment 2009; 44: 2284-2289.

[31] Sadrizadeh S, Afshari A, Karimipanah T, Håkansson U, Nielsen PV. Numerical simulation of the impact of surgeon posture on airborne particle distribution in a 
turbulent mixing operating theatre. Building and Environment 2016; 110: 140147.

[32] Tao Y, Inthavong K, Petersen P, Mohanarangam K, Yang W, Tu J. Experimental visualisation of wake flows induced by different shaped moving manikins. Building and Environment, 2018, 142: 361-370.

[33] Fluent A, Ansys fluent 12.0 users guide, in Ansys Inc vol. Ansys fluent 12.0 users guide, ed. USA: ANSYS, 2009.

[34] Rui Z, Guangbei T, Jihong L. Study on biological contaminant control strategies under different ventilation models in hospital operating room. Building and Environment 2008; 43: 793-803.

[35] Saidi M, Rismanian M, Monjezi M, Zendehbad M, Fatehiboroujeni F. Comparison between Lagrangian and Eulerian approaches in predicting motion of micron-sized particles in laminar flows. Atmospheric Environment 2014; 89: 199-206.

[36] Chen Q, Zhang Z, Prediction of particle transport in enclosed environment, China Particuology 2005; 3: 364-372.

[37] Tao Y, Inthavong K, Tu J, Computational fluid dynamics study of human-induced wake and particle dispersion in indoor environment. Indoor and Built Environment 2016; 26: 185-198.

[38] Wang J, Chow TT. Influence of human movement on the transport of airborne infectious particles in hospital. Journal of Building Performance Simulation 2015; 8: 205-215. 